\title{
The relationship of the structural and intermediate social determinants of health with low birth weight in Iran: A systematic review and meta-analysis
}

\author{
Sharifi N., PhD, Dolatian M., PhD², Fath nezhad kazemi A., MSc ${ }^{3}$, Pakzad R., PhD Candidate ${ }^{4}$, Yadegari \\ L., $\mathrm{MSc}^{5}$ \\ 1. Assistant Professor, Department of midwifery, School of Nursing \& Midwifery, Ilam University of Medical Sciences, \\ Ilam, Iran \\ 2. Assistant Professor ,Department of midwifery \& Reproductive Health, School of Nursing \& Midwifery, Shahid Beheshti \\ University of Medical Sciences, Tehran, Iran, (Corresponding Author), Tel:+98-21-88202517, mhdolatian@ gmail.com \\ 3. MSc of Midwifery, Faculty Member, Department of midwifery, School of Nursing \& Midwifery, Islamic Azad University \\ of Tabriz, Tabriz, Iran \\ 4. PhD Candidate of Epidemiology, Noor Research Center for Ophthalmic Epidemiology, Noor Eye Hospital, Tehran, Iran \\ 5. MSc Midwifery, School of Nursing and Midwifery, Shahid Beheshti University of Medical Sciences, Tehran, Iran
}

\begin{abstract}
Background and Aim: Primary experience of intrauterine period is the essential basis of the life for the embryo. Therefore paying attention to it can lead to reduced health inequities. The aim of this study was to investigate the relationship of the structural and intermediate social determinants of health with low birth weight in Iran

Materials and Methods: This systematic review and meta-analysis was performed based on the studies conducted in Iran. We searched seven databases (Iranmedex, Magiran, SID, Irandoc, PubMed, Google Scholar and Scopus) by using keywords of social determinants of health, low birth weight and equivalents of them to find relevant articles published between 2000 and 2016. Data from relevant studies were extracted by two persons separately and evaluated by using the Stroop checklist. After extracting the required data, they were combined using a random model and the heterogeneity of the studies was evaluated by the I 2 index. STATA-11 software was used for data analysis.

Result: Thirty articles were analyzed in this systematic review and meta-analysis. The sample size included 42142 people. The overall odds ratios for the relationship of the structural and intermediate social determinants of health with LBW were estimated as $1.52(1.24 \%-1.85$ : $\% 95 \mathrm{CI})$ and 2.24 (1.85\%-2.71: \%95 CI) respectively.

Conclusion: Considering the importance of low birth weight in the health of newborns, basic measures should be taken to prevent the occurrence of this problem by identification of its risk factors and people at risk, improvement of living standards and regular prenatal care, counseling before pregnancy and improvement of the nutritional status of pregnant women.
\end{abstract}

Keywords: Low birth weight, Pregnancy outcome, Social determinants of health, Meta analysis.

Received: May 13, 2017 Accepted: Apr 9, 2018 


\title{
ارتباط عوامل ساختارى و بينابينى تعيين كننده هاى اجتماعى سلامت با وزن كم هنكام تولد در ايران: مرور سيستماتيك و متآناليز
}

\author{
نسيبه شريفى'، ماهرخ دولتيان؛، آزيتا فتح نزاد كاظمى"، رضا باكز اد؟، ليلا يادكارى \\ ا. استاديار، گروه مامايى، دانشكده بر ستارى مامايى، دانشكاه علوم يز شكى ايلام، ايلام، ايران.

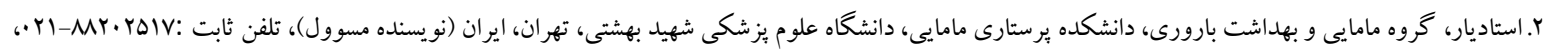 \\ mhdolatian@gmail.com \\ r. كارشناسى ارشد مامايى، عضو هيات علمى گروه مامايى، دانشكده ير ستارى مامايى، دانشكاه آزاد تبريز، تبريز، ايران.

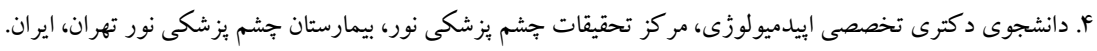

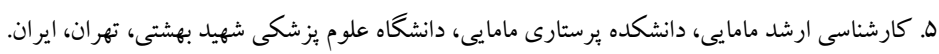

جكيله: زمينه و هدف: تجارب اوليه دوره داخل رحمى براى جنين، يايه حياتى تمام دوران زندگى بوده؛ بنابراين توجه به آن مى تواند منجر به كاهش بى عدالتى سلامت در درون يكك نسل را فراهم نمايد. هدف از يزٔوهش حاضر، تعيين ارتباط بين عوامل ساختارى و بينابينى تعيين كننده هاى اجتماعى سلامت با وزن كم هنگام تولد در ايران بود. روش بروسى: اين مطالعه مرور سيستماتيك و فراتحليل بر اساس مطالعات انجام شده در ايران با جستجوى بيشرفته در بايگًاه هاى اطلاعاتى Scopus و Scholar، PubMed, Iranmedex, Magiran, SID, Irandoc و با استفاده از كليد وازه هاى تعيين كننده هاى اجتماعى سلامت، وزن كم هنگام تولد و معادل انگگليسى آنها از بين كليه مقالات سالهاى .... تدوين گرديد، نتايج مطالعات مرتبط توسط دو نفر به طور مجزا استخراج و با استفاده از جكك ليست استروب مورد ارزيابى قرار كرفتند. سبيس داده ها با استفاده از مدل تصادفى با هم تركيب شده و ناهمگنى مطالعات با استفاده از شاخص 12 بررسى و آناليز داده ها نيز با استفاده از نرم افزار STATA نسخه Iل 1 انجام شد. يافته ها: در اين مرور سيستماتيكك و فراتحليل •r مقاله وارد آناليز شدند. تعداد كل نمونه در مطالعه حاضر FY FY نفر بودند. نسبت

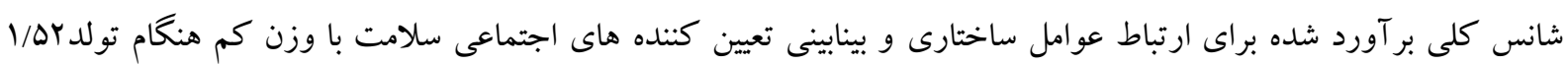

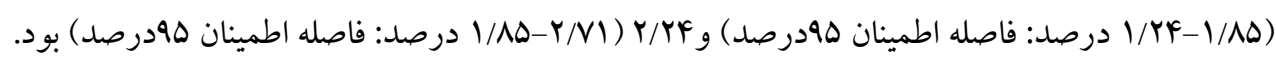
نتيجه كيرى: با توجه به اهميت وزن هنگام تولد در سلامت نوزادان بايد اقدامات اساسى در جهت بيشخيرى از وقوع اين بيامد مهم از طريق شناسايى افراد در معرض خطر و عوامل موثر در بروز آن، بهبود استاندارد هاى زندكى، افزايش مراقبت هاى منظم يره

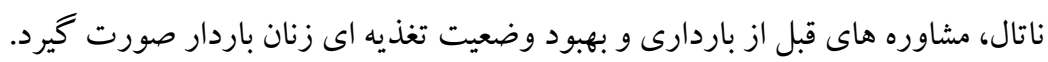
كليد وازه ها: وزن كم هنگام تولد، بيامد باردارى، تعيين كننده هاى اجتماعى سلامت، متآناليز

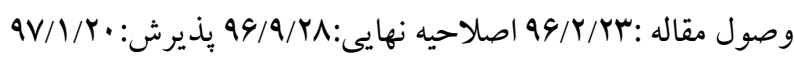


را به شدت تحت تاثير قرار مى دهند و سبب بروز بى عدالتى

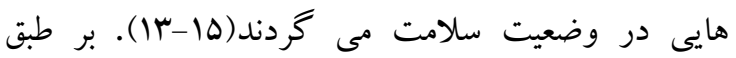
جهارجوب مفهومى كميسيون عوامل اجتماعى موثر بر سلامت سازمان جهانى بهداشت، عوامل كليدى عبارتند از: 1. تعيين كننده هاى اجتماعى ساختارى شامل: تحصيلات،

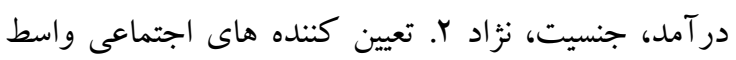

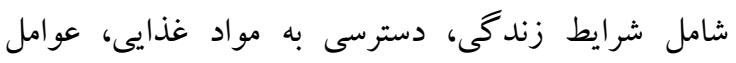
روانى - اجتماعى، عوامل رفتارى r. عوامل زمينه اى سياست

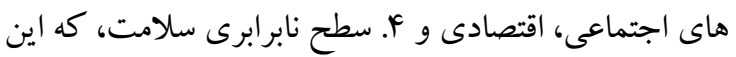

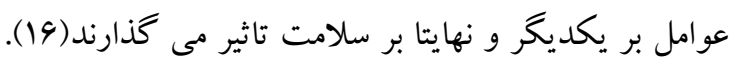
مطالعات عمدتا تمركزشان بر روى ارتباط بين بن بنايج نامطلوب باردارى و تعيين كننده هاى ساختارى سلامت ماند سطح تحصيلات والدين، در آمد خانواده، وضعيت شغلى بدر مى باشد(IV). نتايج مطالعات نشان دهنده ارتباط

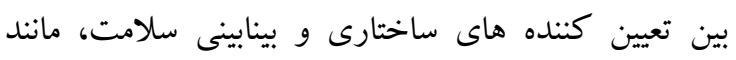
شرايط اجتماعى اقتصادى نامطلوب، فقدان مراقبت هاى

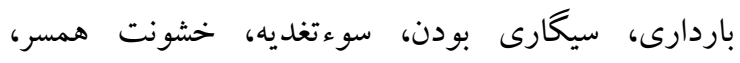
اضطراب مادر، حوادث استرس زا قبل و در طول باردارى و

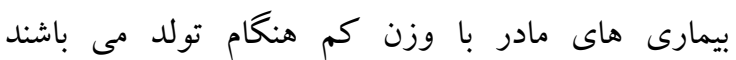
(Y (Y) גוو (I). با توجه به اهميت و شيوع بالاى اين بيامد مهم در باردارى و از آنجايى كه محققان هنوز در نيافته اند كه علت اين بيامد مهم باردارى در نتيجه تقابل و تاثير متقابل فاكتورهاى اجتماعى اقتصادى، يُشكى و روانى است و يا

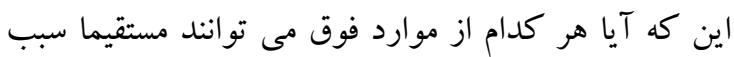
بروز آن شوند؛ بر آن شديم تا مرورى جامع بر مطالعات

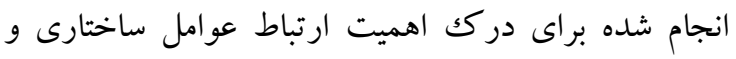

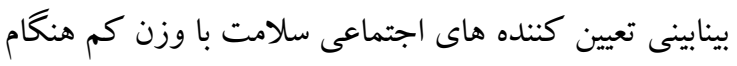
تولد در ايران داشته باشيم.

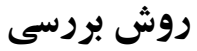

مطالعه مرور سيستماتيك و متا آناليز حاضر، از دى ماه هوسا بـا تا ارديبهشت 994ا جهت تعيين ارتباط بين عوامل ساختارى
مقدمه: وزن كم هنگام تولد، به عنوان يكى از ييامدهاى نامطلوب

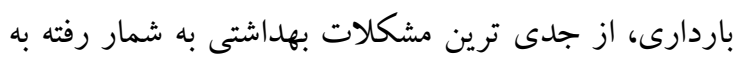

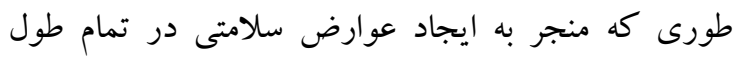
دوره زندگى فرد، از شيرخوارى تا بزر گسالى مى شود (1).

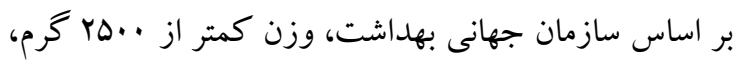
صرف نظر از سن باردارى به عنوان وزن كم هنغام تولد'

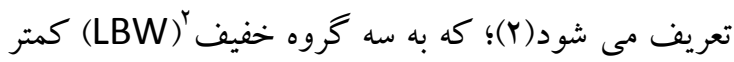

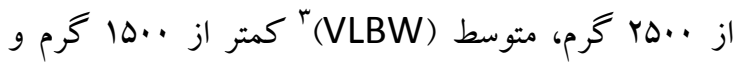

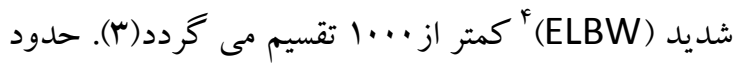

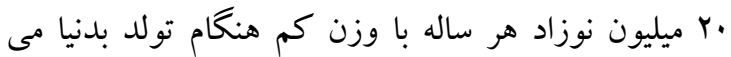

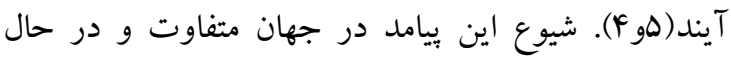

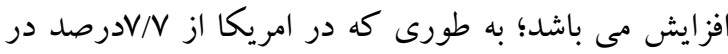

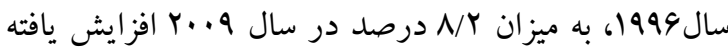
است(9). ميزان كم وزنى در كشورهاى در حال توسعه 9ادرصد بوده و در آسيا بيشتر از آفريقا مى باشد(مولم). در متا آناليز انجام شده در ايران، شيوع كم وزنى هنگ درصد برآورد شده است(9). در مجموع نتايج مطالعات، بيان كنده افزايش اين ييامد نامطلوب باردارى مى بـ

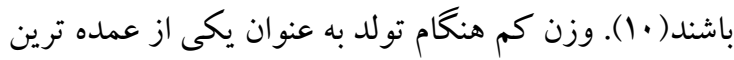
مشكلات سلامت عمومى در بسيارى از كشورها و مناطق مختلف جهان محسوب مى شود(11). كه عوامل متعددى با آن، در ارتباط هستند؛ يكى از اين عوامل، تعيين كننده هاى

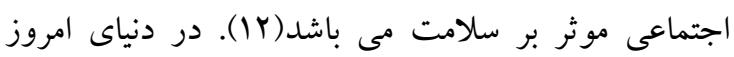

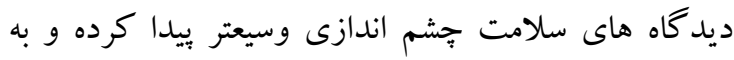

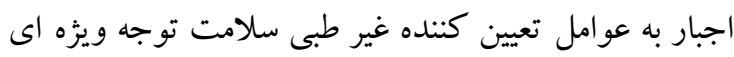

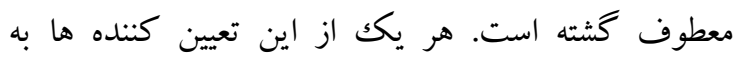

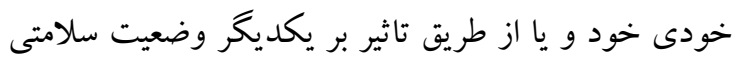

\footnotetext{
${ }^{1}$ low birth weight (LBW)

${ }^{2}$ Low birth weight

${ }^{3}$ Very low birth weight

${ }^{4}$ Extremely Low birth weight
} 
توسط دو نويسنده به طور مستقل مورد بررسى قرار گرفته و در صورت وجود ابهام با انجام بحث، به توافق 'مى رسيدند.

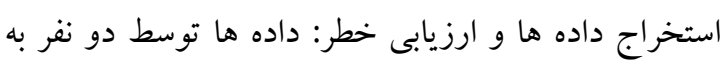

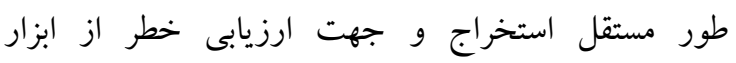
استروبّ استفاده شد و در هر محله در صورت وجود ابهام با انجام بحث، به توافق مى رسيدند.

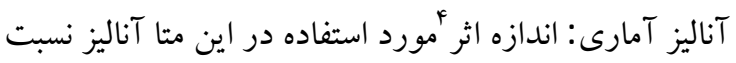

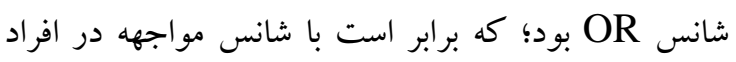
داراى بيامد به شانس مواجهه در افراد سالم (بدون بيامد). بدين دليل از نسبت شانس استفاده شد؛ كه براى مطالعات

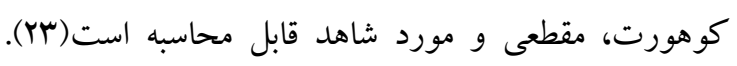

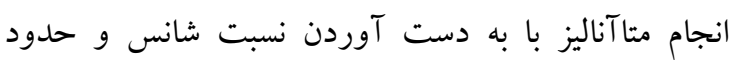

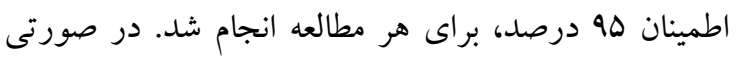

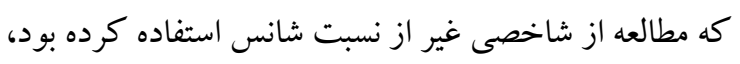
با استخراج ديتا از مطالعه محقق نسبت شانس محاسبه شد. براى محاسبه estimated pool odds ratio از نرم افراز استيتاه ورزن لاست استفاده شد. لازم به ذكر است كه تمام

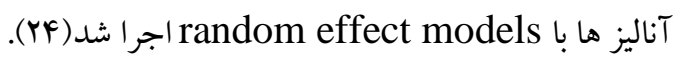
ناهمخونى و سو گرايى انتشارُ؛ در اين مطالعه، وجود

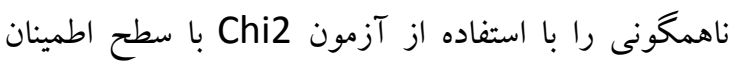
ه•• بررسى و براى بررسى مقدار ناهمگُونى از آماره 12

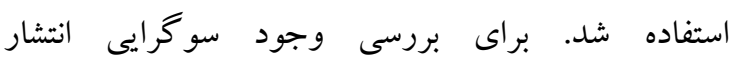

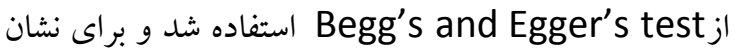

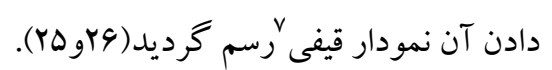

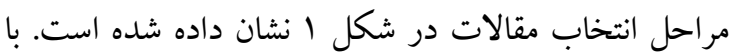

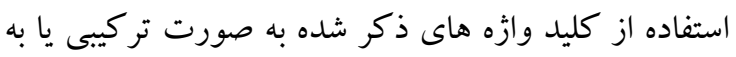
تنهايى، جستجو صورت گرفت و بعد از بررسى مطالعات،

\footnotetext{
${ }^{2}$ Consensus

${ }^{3}$ STROP

effect Size

5 STATA

${ }^{6}$ publication bias

7 funnel plot
}

هجله علمى دانشكاه علوه يِزشكى كردستان / دوره بيست و سوم / ذرداد و تير PRIS
و بينابينى تعيين كننده هاى اجتماعى سلامت با وزن كم

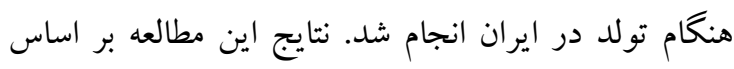

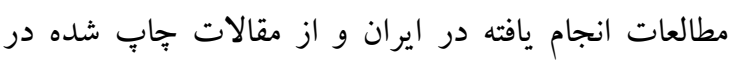
مجلات داخلى و خارجى بدست آمد. مطالعه حاضر براساس سيستم گزارش دهى مطالعات سيستماتيك و متآ آناليز يريسما 'و طبق مراحل زير انجام شد.

استراتزى جستجو: در اين مطالعه مرور نظام مند، بانكك هاى ماى ندائ اطلاعاتى Irandoc ،Iranmedex, Magiran, SID Scopus ،PubMed از استراتزى جستجوى بيشرفته و عملكر هاى متناسب با هر

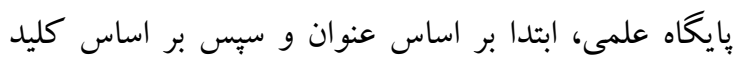
وازه مورد جستجو قرار گرفتند. داده هاى مطالعه، با كليد

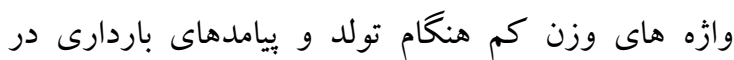

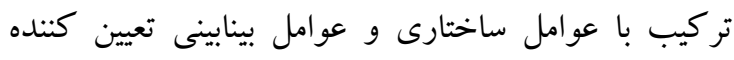

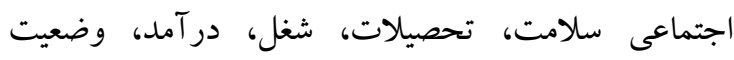

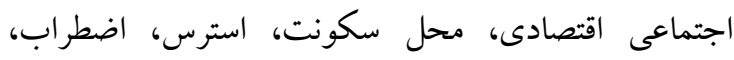

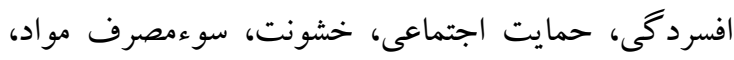

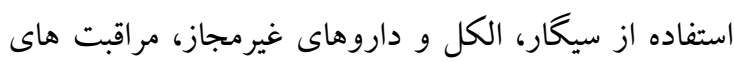

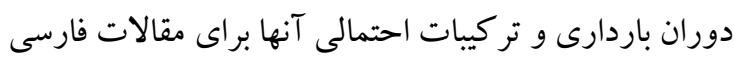

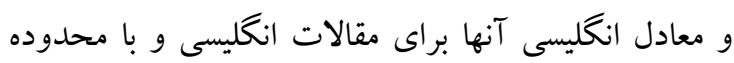

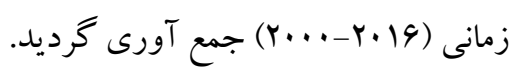
معيارهاى ورود و خروج مطالعه: كليه مقالات انخليسى و و كرديل فارسى داراى متن كامل با طراحى مشاهده ایى(مقطعى، مورد - شاهد و كوهورت) كه در ايران انجام يافته و طبق تعريف،

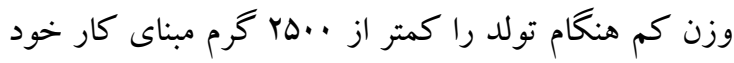

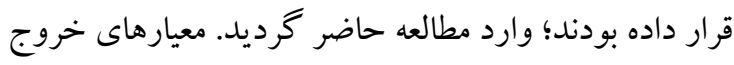

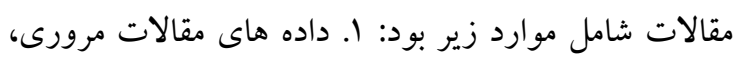

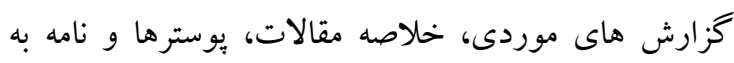

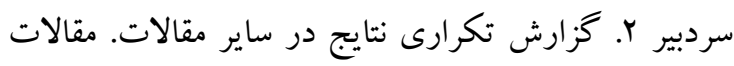

\section{${ }^{1}$ PRISMA}


كرديد و در نهايت ·ب مقاله مورد بررسى و تجزيه تحليل آمارى قرار گرفت. شايان ذكر است كه برخى از مقالات به بررسى جند تعيين كننده با هم برداخته بودند.

بانك هاى اطلاعاتى بررسى شده:

Iranmedex, Magiran, SID ،Irandoc ،google Scholar ‘PubMed, Scopus

$\underline{1652}$

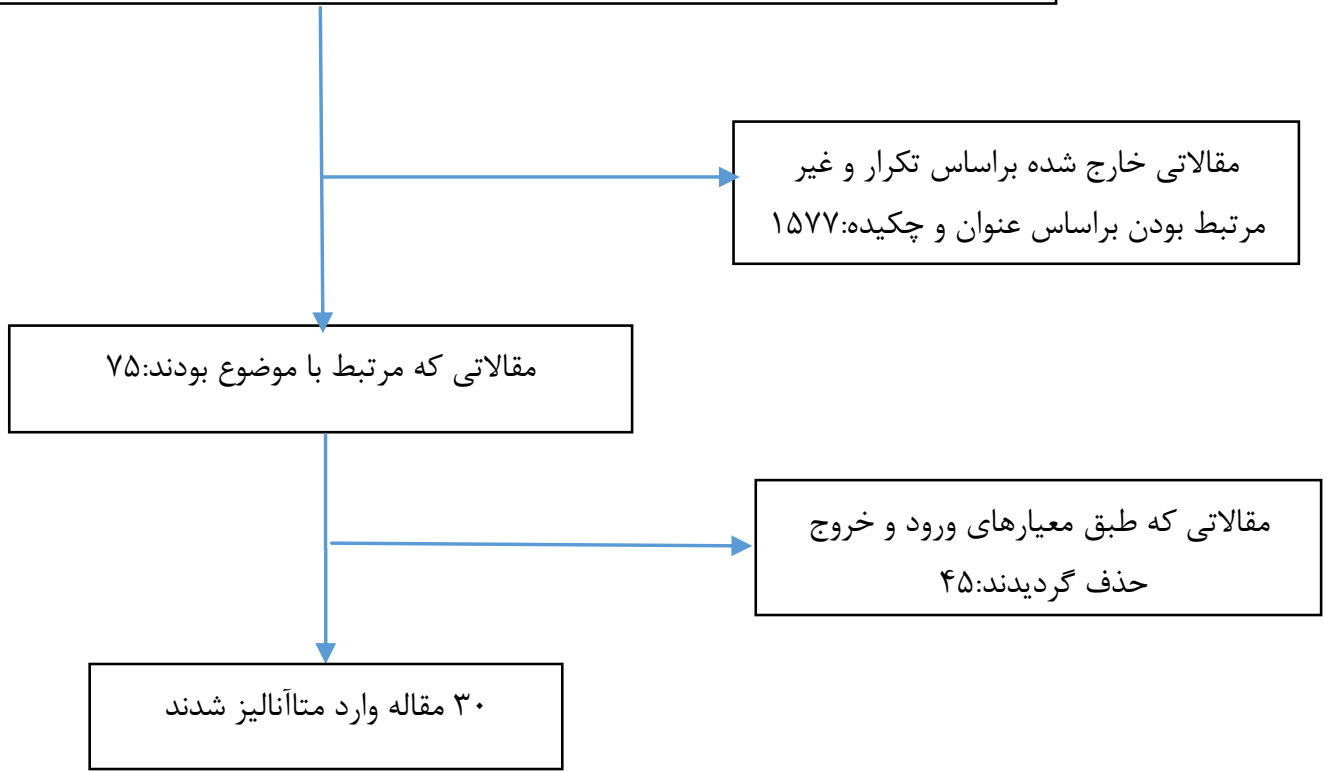

شكل ا: مراحل جستجو و انتخاب مقالات جهت متا آناليز

ساختارى سلامت با وزن كم هنگام تولد را بررسى كرده كه از بين تعيين كننده هاى ساختارى مدل سازمان جهانى بهداشت، سا مطالعه، تحصيلات(YV-M )، 9 مطالعه

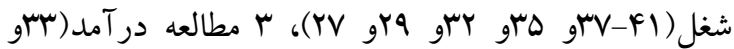

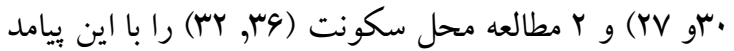
باردارى بررسى نموده اند. در بين عو امل بيناينى تعيين كننده

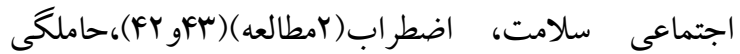

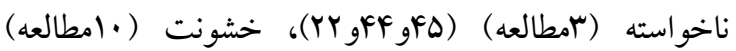

مقالات غير مرتبط با موضوع و تكرارى حذف شدند. در مرحله بعد VD مطالعه انتخاب و بعد از بررسى بر اساس معيارهاى ورود و خروج مطالعه، هDF مطالعه از آنها حذف لـ

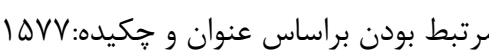

مقالاتى كه طبق معيارهاى ورود و خروج 


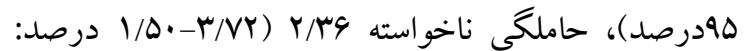

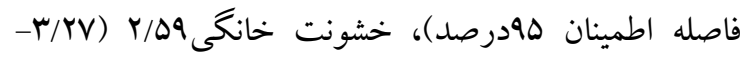
Y/.9 درصد: فاصله اطمينان هودرصد)، رفتارهاى نادرست

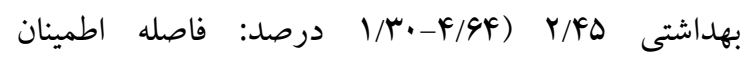

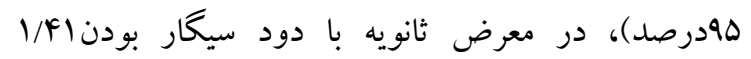

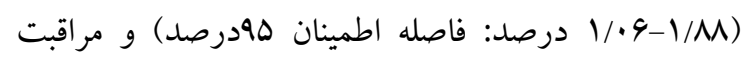
هاى بره ناتال ه/ هودرصد) بر آورد گرديد. كه بيانگر آن است كه زايمان زودرس در مادران داراى اضطراب، رفتار نادرست بهداشتى،حاملكى ناخواسته، مادران خشونت ديده، با سابقه مصرف سيگار، الكل و مواد مخدر و آنهايى كه بطور ثانويه در معرض دود سيگار بودند همجنين مادران با مراقبت هاى ناكافى دوران باردارى، به نسبت ساير مادران بيشتر مى

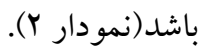
نتايج هتروزنيستى و پِابليكشن باياس: براساس نتايج كاى دو، هتروزنيستى معنى دارى براى عو امل ساختارى سلامت و نيز زير كروه هاى آن از جمله تحصيلات و شغل وجود داشت ( ( P P براى همه آنها). شاخص 12 نيز نشان داد كه مقدار هتروزنيستى براى عوامل ساختارى سلامت و برخى از زير گروه هاى آن از جمله تحصيلات، شغل و در آمد به تريتب 19/9.٪، \% بود (نمودار Y). براى عوامل بينابينى سلامت و نيز برخى از زير گروه هاى آن نيز هتروزنيستى ديده شد كه در نمودار ب مشخص شده است.

ارزيابى سو گرايى انتشار با استفاده از ازمون Begg's and p > نشان داد كه تورش انتشار وجود ندارد(ه Egger's نتايج مقدار هر مطالعه بر روى نمودار قيفى نيز تقريبا متقارن

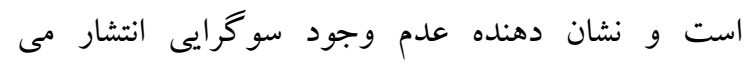

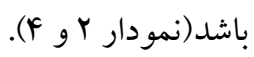

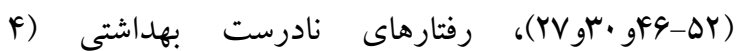

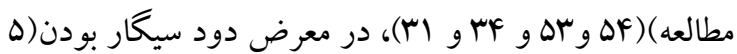
مطالعه)((هله و سه و اس و •r و و و و مراقبت هاى دوران باردارى در F مطالعه بررسى شده بود( با توجه به جدول ا، در ارتباط سنجى تحصيلات با وزن كم هنگام تولد، نتايج f م مطالعه، ارتباط معنى دارى بين تحصيلات مادر با وزن كم هنگام تولد بيان نمودند كه طبق نتايج آنها، شانس وزن كم هنگام تولد در مادران بى سواد

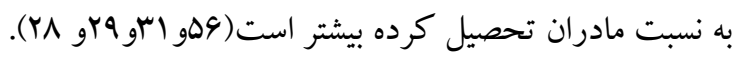
در ارتباط سنجى شغل با اين ييامد باردارى، نتايج F مطالعه، بيانگر اين مطلب مى باشد كه شانس اين بيامد در مادران شاغل به نسبت مادران خانه دار بيشتر است اما در آناليز نهايى ارتباط معنى دارى بين شغل مادر با وزن كم هنگام

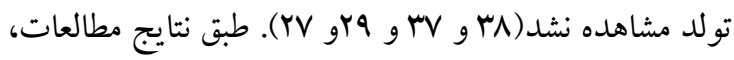
شانس وزن كم هنگام تولد در خانواده هاى با در آمد يايين بيشتر بود(سM و YV). در بررسى ارتباط محل سكونت با وزن كم هنگام تولد، ارتباط معنى دارى مشاهده نشد. نسبت شانس كلى براى ارتباط عوامل ساختارى تعيين كننده

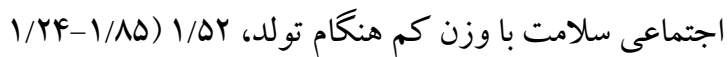
درصد: فاصله اطمينان هودرصد) بر آورد شد و تنها ارتباط

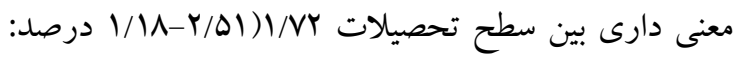

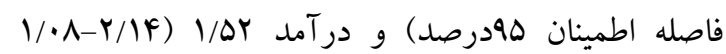
درصد: فاصله اطمينان هودرصد) با وزن كم هنگام تولد به

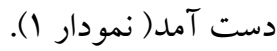
نسبت شانس كلى بر آورد شده براى ارتباط عوامل بينابينى

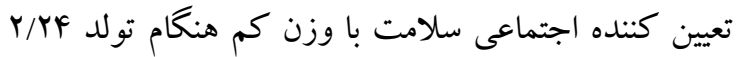

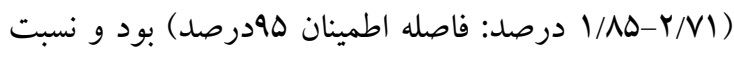
شانس براى هر كدام از زيرمجموعه هاى عوامل بينابينى

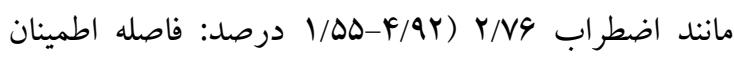


ارتباط عواهل سافتارى و بينابينى... p4

جدول ا: مشخصات مطالعات انجام شده عوامل ساختارى تعيين كننده اجتماعى سلامت با وزن كم هنگام تولد در ايران

\begin{tabular}{|c|c|c|c|c|c|}
\hline \multicolumn{6}{|c|}{ تحصيلات } \\
\hline فاصله اطمينان & نسبت شانس & حجم نمونه & نوع مطالعه & محل مطالعه & نويسنده و سال \\
\hline $1 / \Delta V-r / V \Delta$ & Y/AY & $10 \cdots$ & مقطعى & 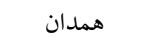 & 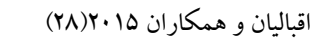 \\
\hline$\cdot / Y \Lambda-G / V^{F}$ & $1 / \mu \wedge$ & $4 .$. & 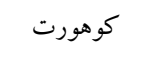 & 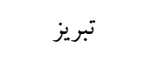 & 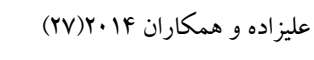 \\
\hline $1 / \cdot 0-1 \cdot / 19$ & $r / r V$ & vo. & مورد شاهد & ت ت تهران & محمودى و همكاران rا ·r(؟ץ) \\
\hline$\cdot / 49-11 / 14$ & $r / \cdot 1$ & rro & مقطعى & 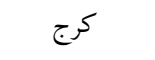 & باهرى و همكاران r| r(r) (r) \\
\hline$\Delta / Y r-\mid Y / F \Lambda$ & $\Lambda \cdot \wedge$ & $f \cdot$. & 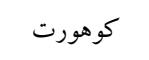 & 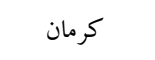 & رنجبر و همكاران II ب(1) \\
\hline$\cdot / a q-1 / \Delta$ & $1 / 19$ & Fol. & 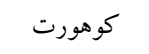 & 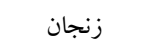 & 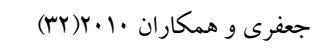 \\
\hline$\cdot / A F-1 / 9 \pi$ & $1 / I V$ & YMA & مقطعى (- مقى & كر كَان & وقارى و همكاران 9... Y(rT) \\
\hline$. / 94-19 / .9$ & $\mathrm{r} / \wedge \mathrm{V}$ & rVHF & 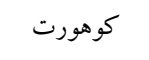 & 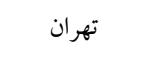 & 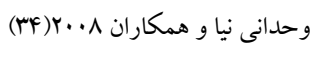 \\
\hline $1 / Y 9-Y / Y G$ & $1 / 99$ & $11 \cdot v$ & مقطعى (- مقى & 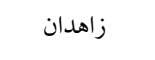 & 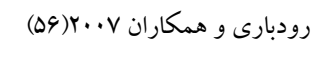 \\
\hline$\cdot / 9 F-r / 9 r$ & $1 / 94$ & rrrA & مقطعى & بابل & 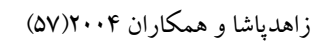 \\
\hline $1 / \Gamma \Lambda-r / \mu r$ & $r / l F$ & $11 \cdot k \Delta$ & - & - & كل تحصيلات \\
\hline \multicolumn{6}{|c|}{ شغل } \\
\hline فاصله اطمينان & نسبت شانس & حجم نمونه & نوع مطالعه & محل مطالعه & نويسنده و سال \\
\hline $1 / \Delta r-r / 99$ & $r / \cdot r$ & $4 \cdot \cdot$ & كوهورت & تبريز & عليز اده و همكاران (YV)Y IF \\
\hline$\Gamma / \mu F_{-} \Lambda / \Delta V$ & $\Delta / r \Delta$ & va. & مورد شاهد & 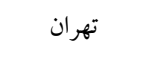 & محمودى و همكاران rا •r(Ya) \\
\hline $1 / 19-r / 0$. & $r / \cdot F$ & fr. & 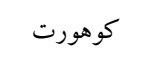 & 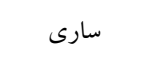 & طيبى و همكاران r| ·r(^) \\
\hline $1 / r \Delta-\Delta / A r$ & $r / v \cdot$ & $\Delta \wedge 9 \vee$ & مقطعى & 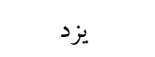 & كلستان و همكاران IIV)r) \\
\hline$\cdot / 94-1 / 99$ & $1 / 49$ & FOI. & 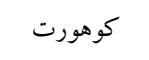 & 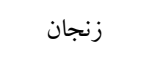 & 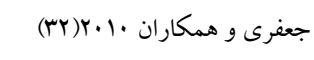 \\
\hline$\cdot / \Delta V-1 / V 1$ &.$/ 99$ & $Q 41$ & مقطعى & يزد & 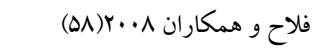 \\
\hline$\cdot / 49-Y / \cdot 1$ &.$/ 99$ & $11 \cdot v$ & مقطعى (مقى & 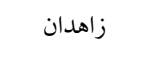 & 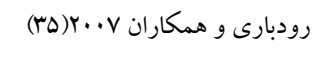 \\
\hline $.1 \cdot 9-Y / 4 r$ & $\cdot / r q$ & 1914 & 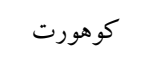 & 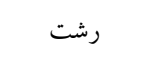 & مداح و همكاران هـ•r(F) \\
\hline$\cdot / r 9-1 / 14$ & $\cdot / \Delta F$ & IQYV & مقطعى & قم & كريميان و همكاران F...F(F) (F) \\
\hline $1 / \cdots-r / r q$ & V/DF & 11.99 & - & - & كل كل كل \\
\hline \multicolumn{6}{|c|}{ درآمد } \\
\hline فاصله اطمينان & نسبت شانس & حجم نمونه & نوع مطالعه & محل مطالعه & نويسنده و سال \\
\hline $1 / \Delta r-r / 99$ & $r / \cdot r$ & $9 \cdot$. & كوهورت & تبريز & 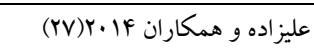 \\
\hline$\cdot / \Delta 9-1 / A$ & $1 / \cdot 1$ & mo & مقطعى & 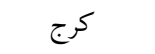 & 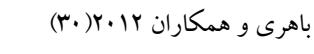 \\
\hline $1 / 1 \cdot-1 / \wedge F$ & $1 / 4 r$ & YMAl & مقطعى - مقى & كر كَان & وقارى و همكاران 9... Y(rT) \\
\hline $1 / \cdot \Lambda-Y / I F$ & l/Qr & rNIS & - & - & كل در آمد \\
\hline \multicolumn{6}{|c|}{ محل سكونت } \\
\hline فاصله اطمينان & نسبت شانس & حجم نمونه & نوع مطالعه & محل مطالعه & نويسنده و سال \\
\hline$. / 9 Y-1 / 49$ & $1 / 19$ & Fol. & 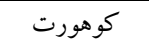 & زنجان & 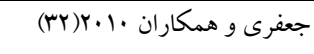 \\
\hline$\cdot / 94-1 / r$ & $\cdot / M$ & rrYA & مقطعى (- مقى & بابل & 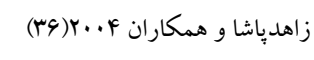 \\
\hline$\cdot / \sqrt{ } 9-1 / r \Delta$ & $1 / r$ & aVru & - & - & كل محل سكونت \\
\hline
\end{tabular}




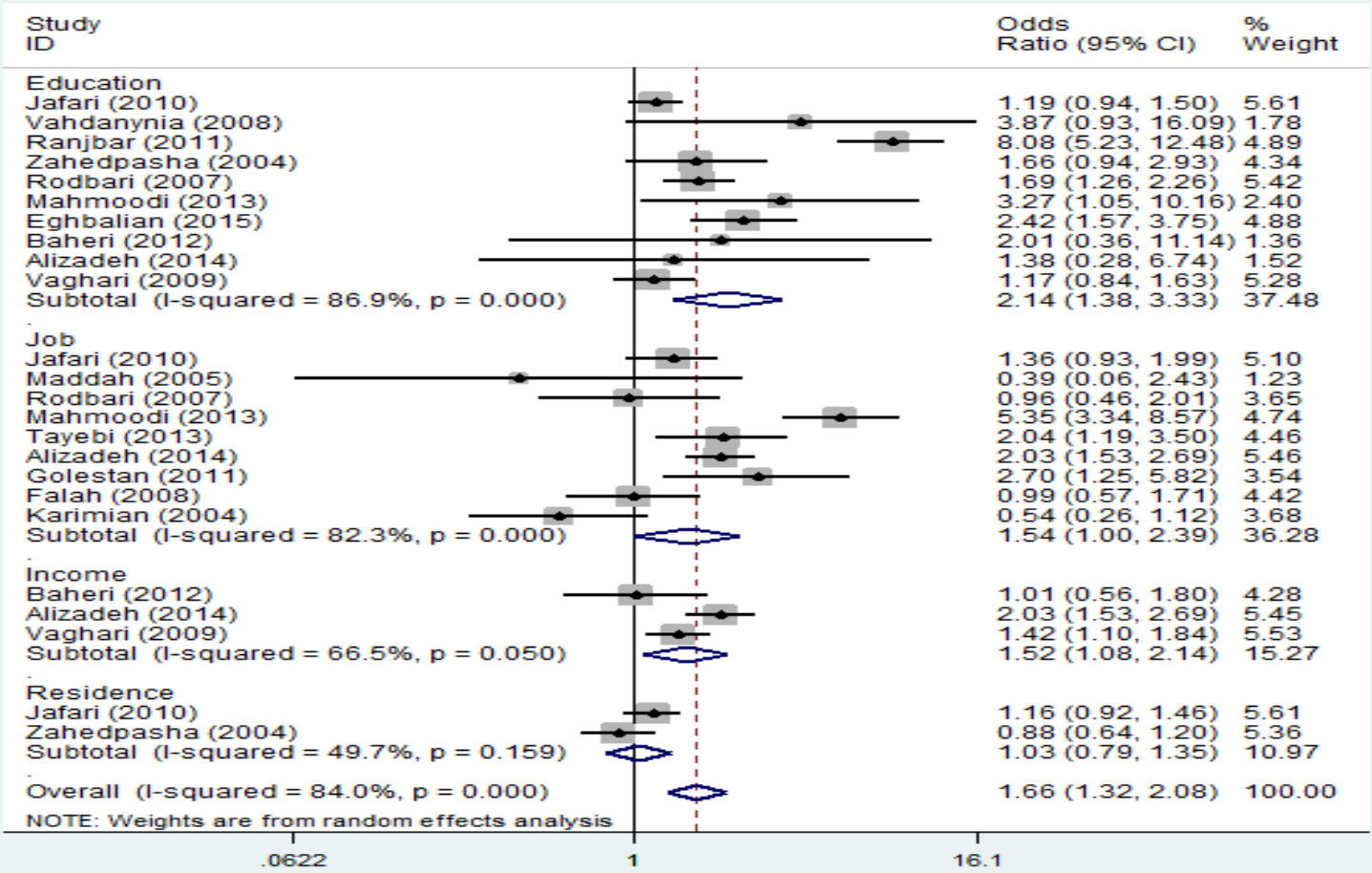

نمودار ا: عوامل ساختارى سلامت به تفكيك نويسنده، سال، نسبت شانس و فاصله اطمينان هودرصد، هر باره خط، طول فاصله اطمينان را نشان مى دهد.

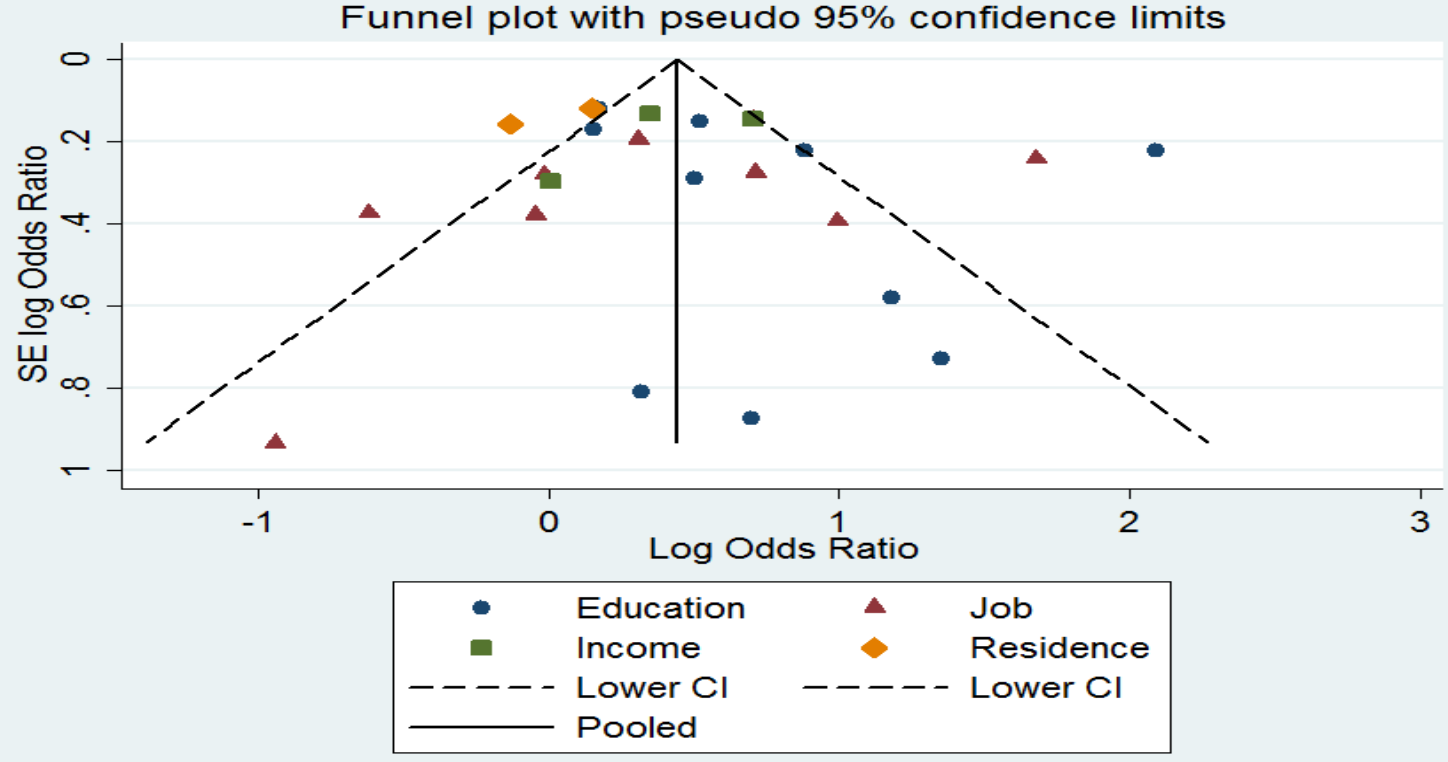

نمودار rfunnel plot براى مطالعات وارد شده به متآ باليز عوامل ساختارى سلامت بر حسب نوع عامل ساختارى 


\begin{tabular}{|c|c|c|c|c|c|}
\hline \multicolumn{6}{|c|}{ اضطر اب } \\
\hline فاصله اطمينان & نسبت شانس & حجم نمونه & نوع مطالعه & محل مطالعه & نويسنده و سال \\
\hline$\cdot / A F-Y H / F \Lambda$ & $F / F F$ & 109 & كوهورت & قم & 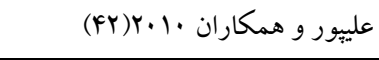 \\
\hline $1 / r q-p / v q$ & $r / 09$ & $9 \Lambda \mathrm{r}$ & كوهورت & بابل & 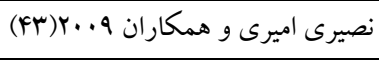 \\
\hline $1 / \Delta \Delta-r / a r$ & Y/VG & $\Lambda \mu$ & - & - & كل اضطراب \\
\hline \multicolumn{6}{|c|}{ حاملكى ناخواسته } \\
\hline فاصله اطمينان & 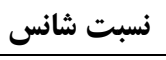 & حجم نمونه & نوع مطالعه & محل مطالعه & نويسنده و سال \\
\hline$|/ \wedge \Delta-r / Y|$ & $r / F F$ & $4 .$. & كوهورت & 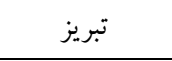 & 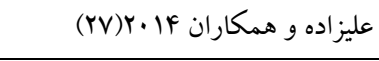 \\
\hline$\cdot / 99-Y / 99$ & $1 / v$ & r.. & موردشاهد & 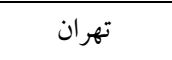 & موزينى و همكاران IFF r. IF \\
\hline I/9N-rY/QV & $V / F \Delta$ & $r .$. & موردشاهد & ت تهران & 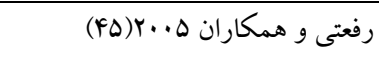 \\
\hline $1 / Q \cdot-r / V r$ & $r / T^{\prime}$ & $11 \ldots$ & - & - & كل حاملكَى هاى ناخو استه \\
\hline \multicolumn{6}{|c|}{ خشونت } \\
\hline فاصله اطمينان & 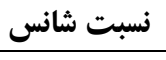 & حجم نمونه & نوع مطالعه & محل مطالعه & نويسنده و سال \\
\hline $1 / \Delta \cdot-\Delta / 9$ & $r / 9$. & $|49|$ & كوهورت & مازندران & 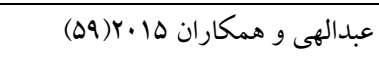 \\
\hline$\cdot / \Delta 1-F / r \Delta$ & $1 / 49$ & $4 .$. & كوهورت & 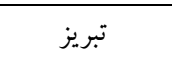 & عليز اده و همكاران IF) (YV) \\
\hline $1 / \cdot 1-F / M$ & T/Yr & ir.. & مقطعى & 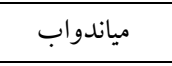 & حسن و همكاران rا •r(F) (F) \\
\hline $1 / Y \Delta-r / \cdots$ & $1 / 94$ & M & مقطعى & 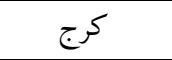 & باهرى و همكاران r إ.r(·r) \\
\hline $1 / \Lambda r-V / 9 \Lambda$ & r/VQ & FOI. & كوهورت & زنجان & 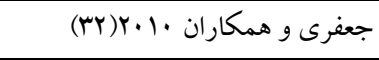 \\
\hline M & $1 / 9$ & rוr & مقطعى & خرم آباد & 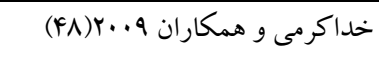 \\
\hline$r / r \cdot-r V / V G$ & $\Lambda / \cdots$ & $\Delta \ldots$ & مقطعى & צֶ: & دولتيان و همكارانq ... (Fq) \\
\hline $1 / 9 \cdot-r / 1 r$ & Y/YF & 949 & موردشاهد & كوهيلويه و & انصارى و همكاران 9.+r( •(ه) \\
\hline & & & & بوير احمد & \\
\hline$r-F / F q$ & $r / \cdot$ & 949 & موردشاهد & كوهگيلويه و & ضيغمى و همكاران ه •.r (DI) \\
\hline & & & & بوير احمد & \\
\hline$r / 9 \cdot-r / 99$ & $r / 1$. & TYVD & مقطعى & بابل & 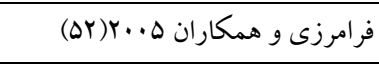 \\
\hline$r / \cdot 9-r / Y V$ & $r / \Delta Q$ & $1 r \Delta 99$ & - & - & كل خشونت \\
\hline \multicolumn{6}{|c|}{ رفتارهاى بهداشتى نادرست } \\
\hline فاصله اطمينان & 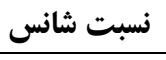 & حجم نمونه & نوع مطالعه & محل مطالعه & نويسنده و سال \\
\hline $1 / .9-r / \Delta r$ & $r / 19$ & f.. & كوهورت & كرمان & رنجبر و همكاران I|+r( اس) \\
\hline $1 / 99-1 \cdot / M$ & F/AY & rVHF & كوهورت & ت ت تهران & 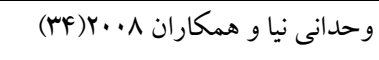 \\
\hline$\cdot / \cdot r-Y / Y$ & $\cdot /$ YS & F.F & موردشاهد & 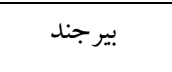 & طاهرى و همكاران V •. (DF) \\
\hline $1 / \Delta r-F / A r$ & $r / V I$ & Friv & مقطعى & 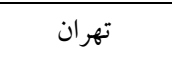 & 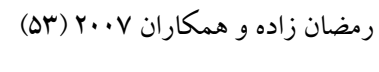 \\
\hline $1 / r \cdot-f / 94$ & T/FQ & $M \Delta \Delta$ & - & - & كل رفتارهاى ناسالم \\
\hline
\end{tabular}




\begin{tabular}{|c|c|c|c|c|c|}
\hline \multicolumn{6}{|c|}{ در معرض ثانويه دود سيكار } \\
\hline فاصله اطمينان & نسبت شانس & حجم نمونه & نوع مطالعه & محل مطالعه & نويسنده و سال \\
\hline $1 / \cdots-1 / \mu$ & $1 / 1 F$ & $4 .$. & كوهورت & 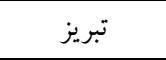 & 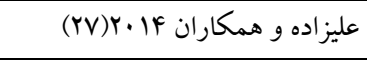 \\
\hline $1 / \cdot V-F / 9 \Lambda$ & Y/YF & 1.94 & موردشاهد & اردبيل & ميرزارحيمى و همكاران سا ·r(·) \\
\hline $1 / \cdots-14 / 90$ & r/Ar & mo & مقطعى & كرج & باهرى و همكاران r|r.r(r) \\
\hline$\cdot / 9 \Delta-r / V \mu$ & $1 / 91$ & f.. & كوهورت & 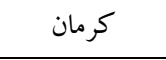 & 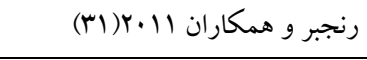 \\
\hline - $/ 1 \mid-1 / 94$ & $1 / r \Delta$ & Friv & مقطعى & 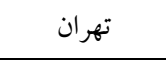 & رمضان زاده و همكاران V...r(ه) \\
\hline $1 / .9-1 / M$ & $|/ 4|$ & 9VID & - & - & كل در معرض ثانويه دود سيخار \\
\hline \multicolumn{6}{|c|}{ مر اقبتهاى باردارى } \\
\hline فاصله اطمينان & 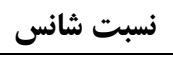 & حجم نمونه & نوع مطالعه & محل مطالعه & نويسنده و سال \\
\hline $1 / r q-Y / F q$ & $1 / \wedge \Delta$ & $4 .$. & 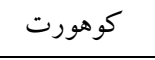 & 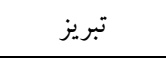 & عليز اده و همكاران IF) (YV IF \\
\hline$r / \cdot q-r / \Lambda \Delta$ & Y/AF & fr. & كوهورت & 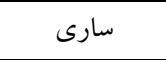 & 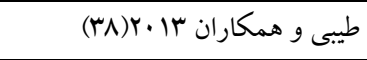 \\
\hline $1 / Y 9-Y / Y \Delta$ & $1 / V \Delta$ & Fol. & كوهورت & 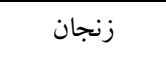 & جعفرى و همكاران · PFV)Y. \\
\hline $1 / M F-Y / A G$ & $1 / 99$ & $11 \cdot \mathrm{V}$ & مقطعى & زاهدان & رودبارى و همكاران V.•ra(r) \\
\hline $1 / G 4-Y / \Delta \Delta$ & $r / \cdot \Delta$ & $994 \mathrm{~V}$ & - & - & كل مر اقبت هاى بره ناتال \\
\hline
\end{tabular}

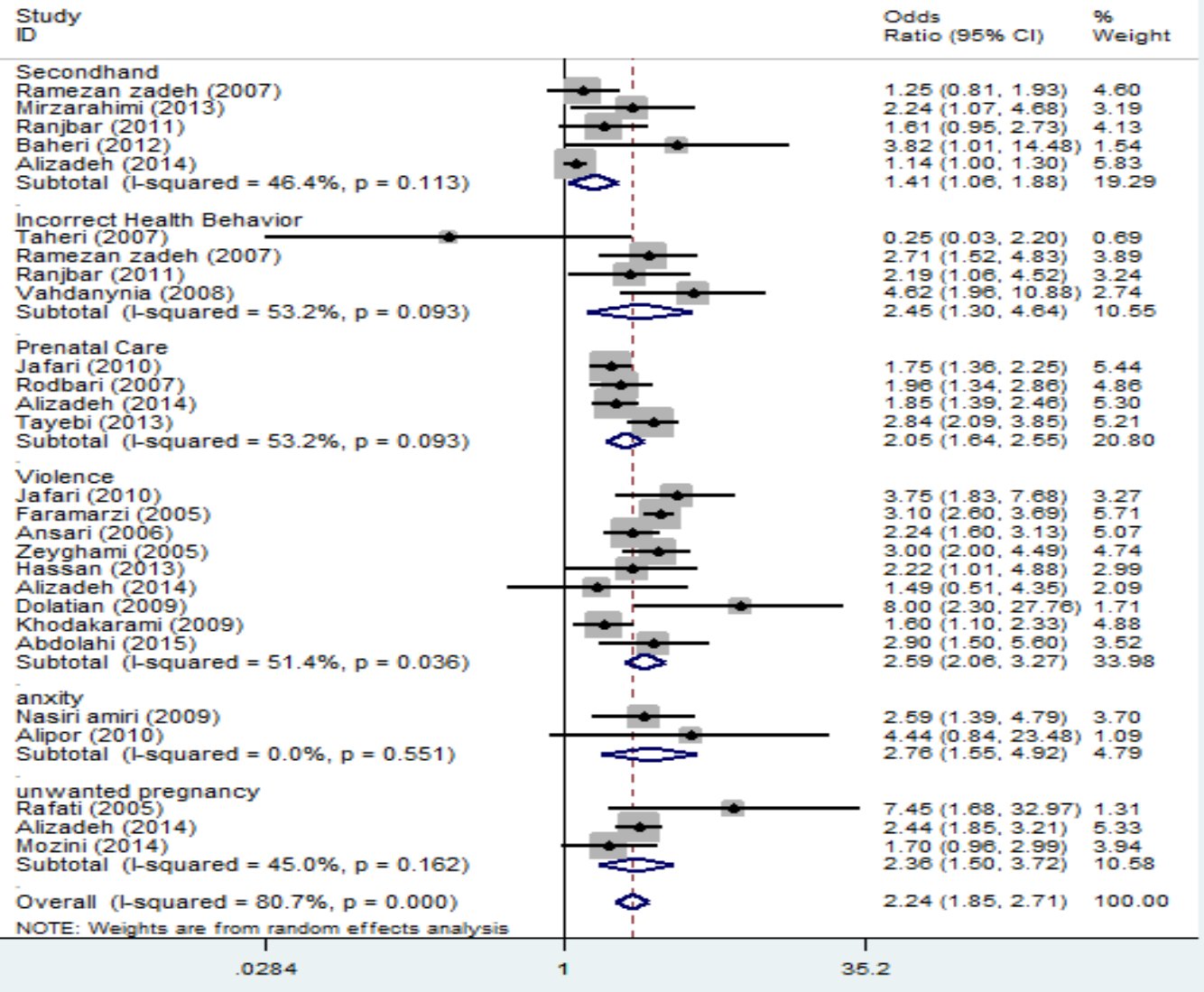

نمودار "r: عوامل بينابينى سلامت به تفكيكك نويسنده، سال، نسبت شانس و فاصله اطمينان هودرصد، هر باره خط، طول فاصله اطمينان را نشان مى دهد. هجلم علمى دانشكاه علوه يِزشكى كردستان / دوره بيست و سوه / ذرداد و تير IMqV 


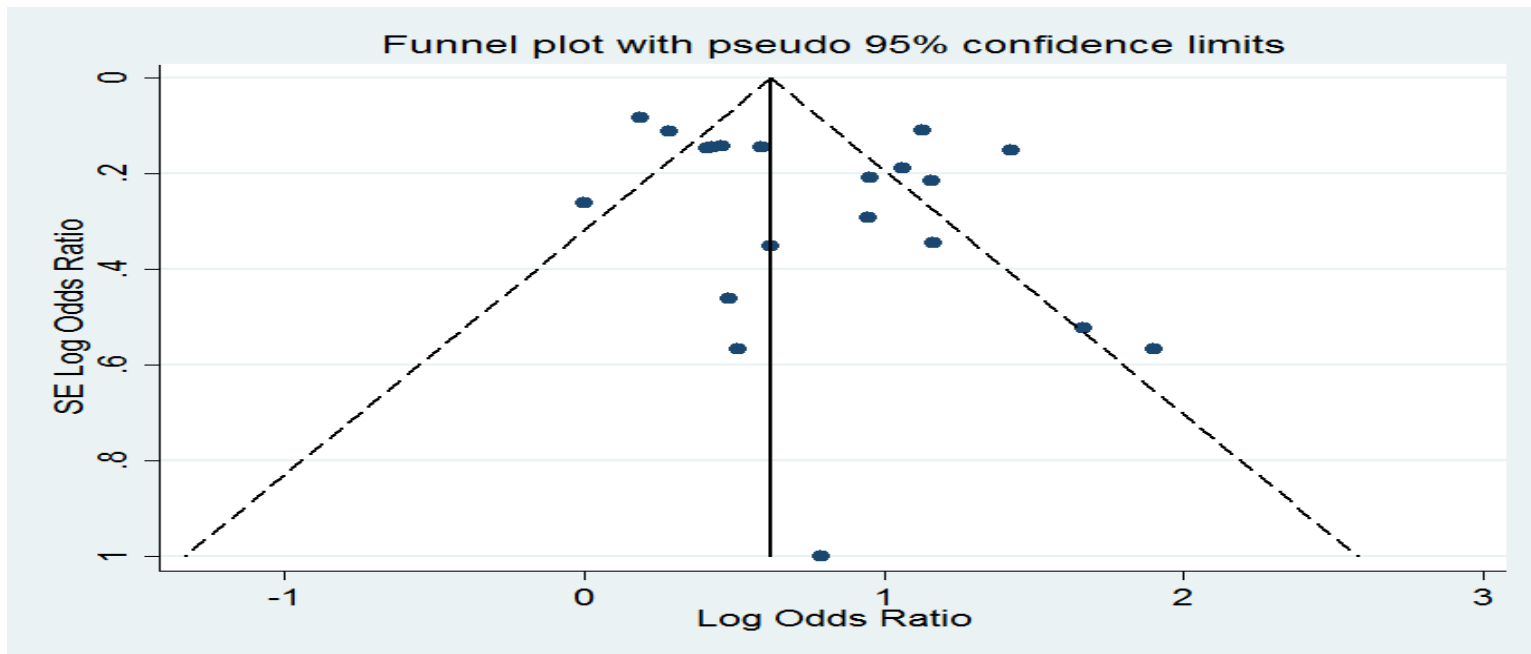

نمودار funnel plot براى مطالعات وارد شده به متا آناليز عوامل بينابينى سلامت

ساختارى تعيين كننده اجتماعى سلامت ذكر شده، بيشترين عواملى كه در بروز كم وزنى هنكام تولد موثر بودند عبار تند از تحصيلات، شغل، درآمد و محل سكونت، كه در بين معرف هاى اقتصادى اجتماعى، تحصيلات مادر بيشترين عامل خطر بود. طبق آناليز بدست آمده، تحصيلات و درآمد از تعيين كننده هاى ساختارى سلامت با وزن كم هنگام تولد ارتباط معنى دارى داشتند. در ارتباط سنجى تحصيلات با

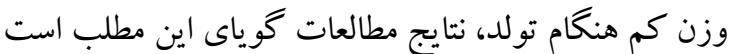
كه شانس وزن كم هنگام تولد در مادران بى سواد به نسبت مادران تحصيل كرده بيشتر است(هه و و در ارتباط سنجى شغل و محل سكونت با وزن كم هنكام تولد، ارتباط معنى دارى مشاهده نشد. همجنين شانس اين يايامد در خانواده هاى با در آمد بايين بيشتر بود(بس و وVV). سر انجام باردارى بسيار متاثر از وضعيت اقتصادى و اجتماعى بأي كه مادر در آن زندگى مى كند. اختلافات اقتصادى و اجتماعى يكى از مولفه هاى سلامت نوزادان و سرانجام

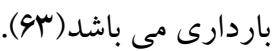

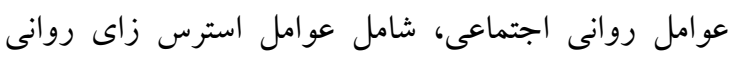

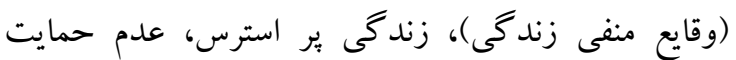

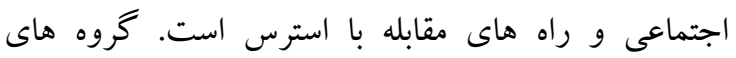
همان طور كه در يافته ها هم بيان شد در اكثريت مقالات مورد مطالعه فقط برخى از تعيين كننده هاى اجتماعى سلامت بررسى شده كه به ترتيب مورد بحث قرار خواهد

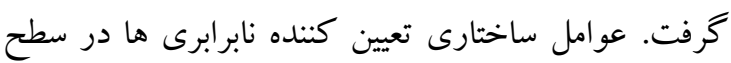
سلامت و شرايط روانى - اجتماعى دو عامل مهم موثر بر سلامت هستند، عوامل اقتصادى و اجتماعى بر عوامل روانى

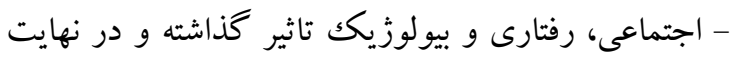
كيفيت وضع بهداشت و سلامت را تحت تاثير قرار مى دهند. بسيارى از اين عوامل در زندگى افرادى كه شرايط اقتصادى اجتماعى پايينى دارند؛ حالت تجمعى داشته و با يكديخر تداخل دارند(19). وضعيت اقتصادى اجتماعى، ساختار بيجيجيده اى است كه معمولا براى توصيف نابرابرى هاى اجتماعى استفاده شده و عموما با تحصيلات و درآمد سنجيده مى شوند؛ اما بعيد به نظر مى رسد كه شرايط اقتصادى اجتماعى نامساعد، عاملى مستقيم و غيروابسته براى ييامدهاى باردارى باشد؛ بلكه احتمالا به واسطه ايجاد رفتارهاى غيربهداشتى، مواجهه با استرس و واكنش هاى بـاى بهائ روانى نسبت به استرس منجر به كوتاه شدن مدت باردارى

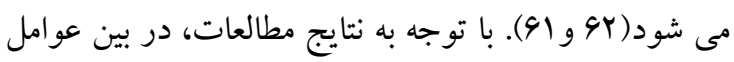


بسيارى از مطالعات ذكر شده است(·V و و99). در بررسى

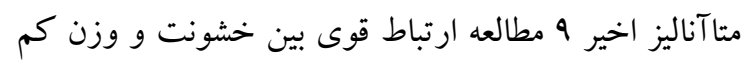

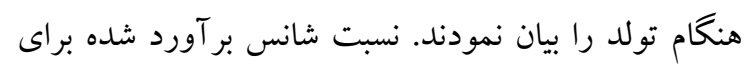
خشونت Y/DQ

$$
\text { هودرصد) برآورد گرديد. }
$$

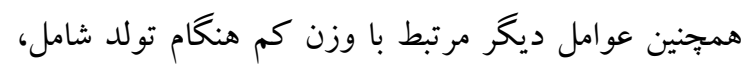

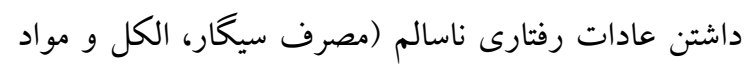
مخدر)، در معرض دود سيگار بودن خانم باردار و داشتن

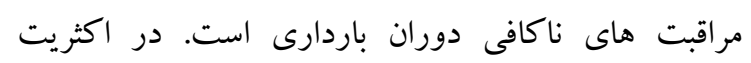
مطالعات داخلى و خارجى تاثير اين عوامل را بر بيامدهاى داى دافي

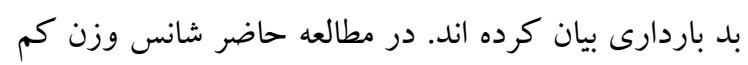

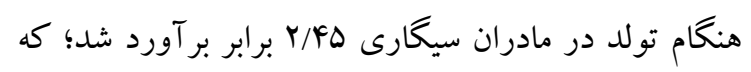

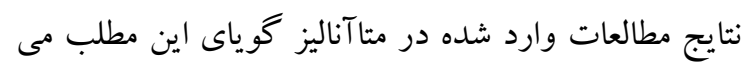

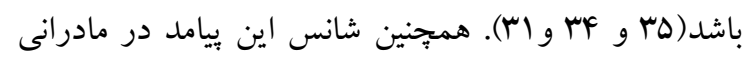

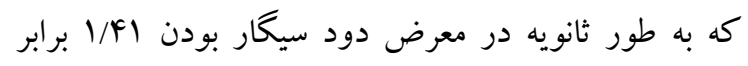

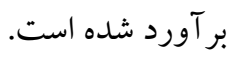
نتايج مطالعات همخى ارتباط قوى بين دريافت ناكافى مراقبت هاى دوران باردارى، زمان مراجعه و تعداد ويزيت

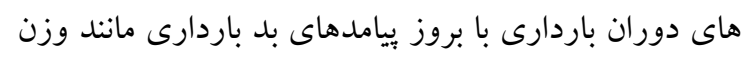

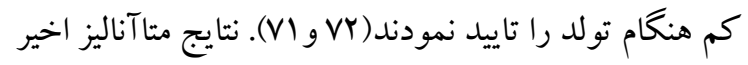

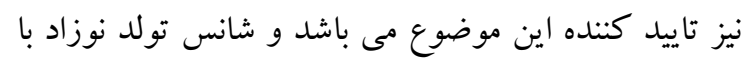

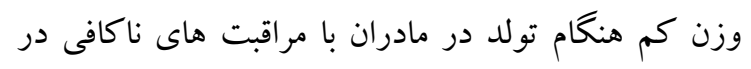

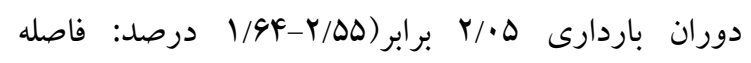

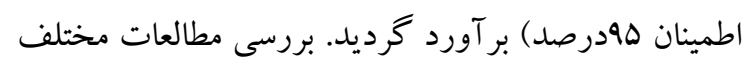

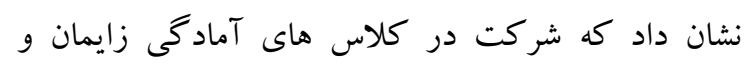

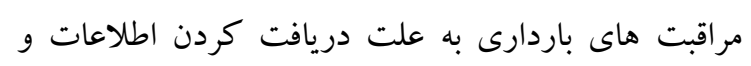

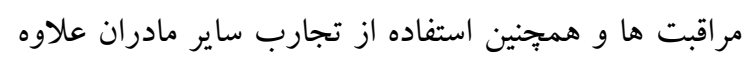
بر كاهش اضطراب، مى تواند نقش مهمى در كاهش بيمارى

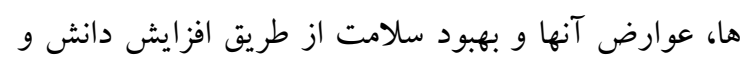

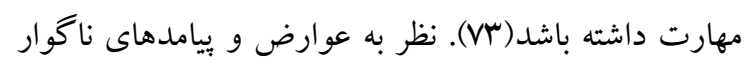

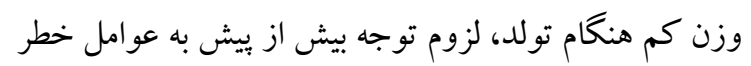

مختلف اجتماعى با درجات متفاوتى از تهديد، استرس و

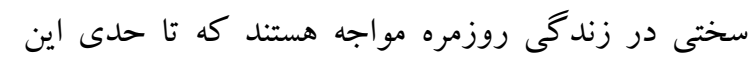

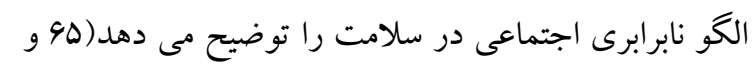

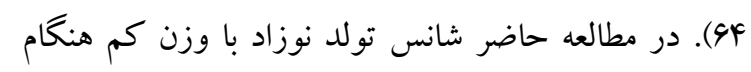

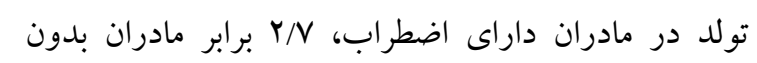

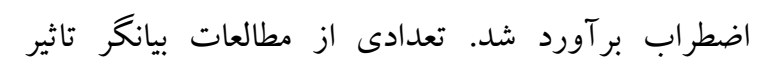

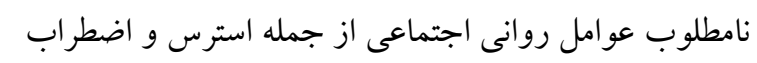

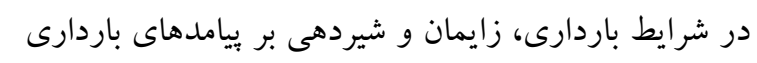

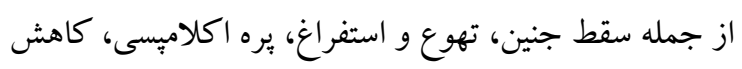
وزن، زايمان زودرس، وزن كم هنكام تولد، مهار سيستم

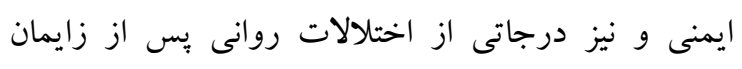

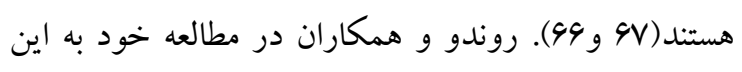

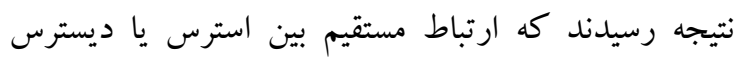
روانى اجتماعى مادرى و وزن كم هنگام تولد، زايمان

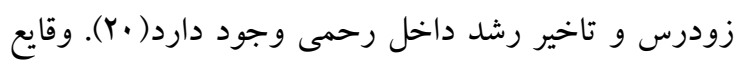

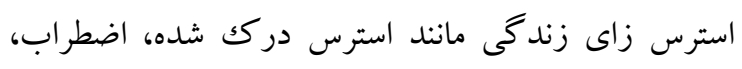

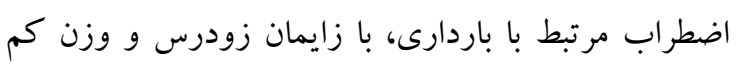
هنگام تولد در ارتباط هستند (91).

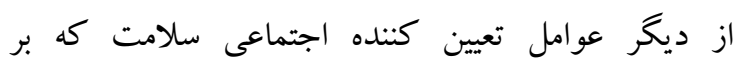
بيامدهاى باردارى تاثير كذار هستند؛ حاملكى هاى ناخواسته و خشونت مى باشند كه در زروه عوامل بينابينى تعيين كننده اجتماعى سلامت دسته بندى مى شوند. طبق نتايج مطالعات

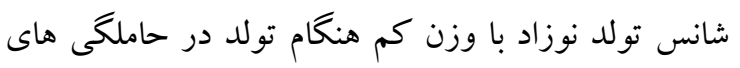
ناخو استه بيشتر مى باشد كه نتايج مطالعه عليز اده و همكاران

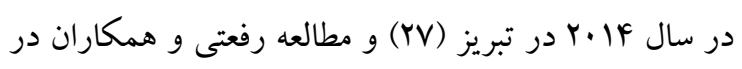
تهران گوياى اين مطلب مى باشد(Y)

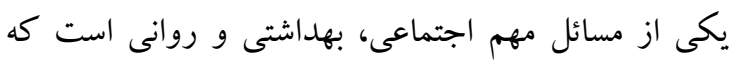

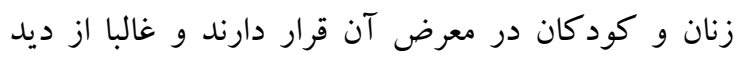

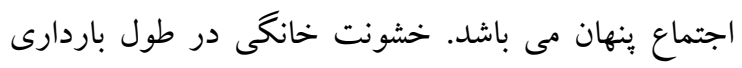

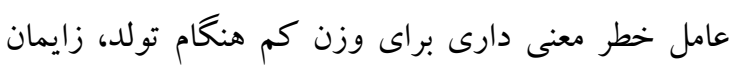

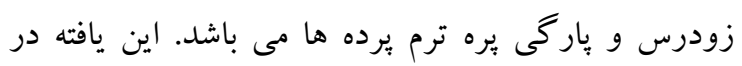


مطالعه حاضر مى توان به ا. در نظر گرفتن صرف مطالعات انجام شده در ايران r. عدم دستيابى به تمامى مقالات و و كزارش هاى منتشر نشده اشاره نمود.

\section{نتيجه كيرى}

با توجه به اهميت وزن هنكام تولد در سلامت نوزادان بايد

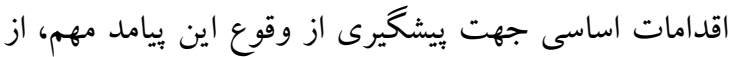
طريق شناسايى افراد در معرض خطر و عوامل موثر در بروز

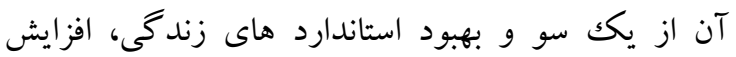
مراقبت هاى منظم بره ناتال، مشاوره هاى قبل از باردارى و و

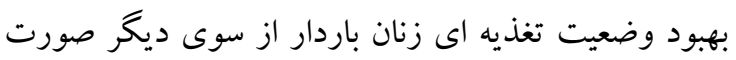

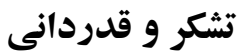

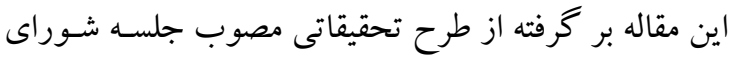

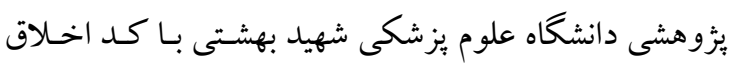

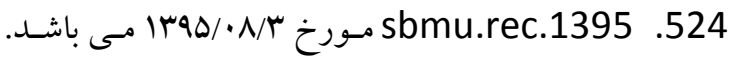
بـــين وسـيله از همكـارى و مسـاعدت مسـئولين دانشـكده،

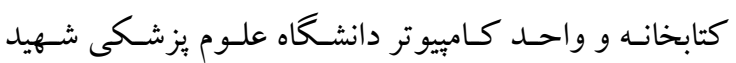
بهشتى جهـت همكسارى در جسـتجوى مقــالات تشـكر و و

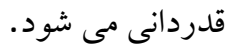

اين بيامد مهم باردارى مى تواند از اهميت بسيار بالايى

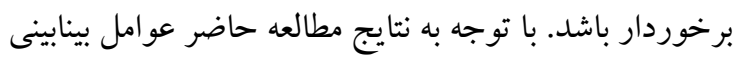
سلامت مانند عوامل روانى (اضطراب، خشونت، باردارى بـائ ناخواسته)، عوامل رفتارى (رفتارهاى نادرست بهداشتى و در

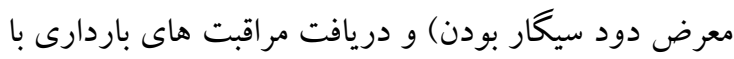

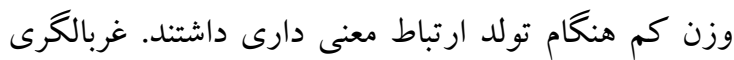
عوامل روانى و رفتارى در هر سه ماهه باردارى ضرورى به

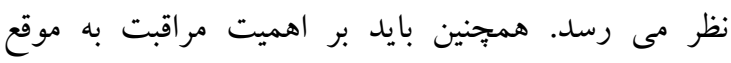

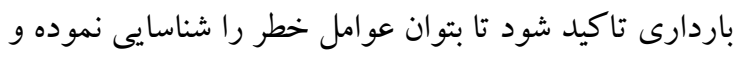
از بار مالى و عاطفى كه اين بيامد نامطلوب بر خانواده ها و جامعه تحميل مى نمايد بيشخيرى نمود. نقاط قوت و ضعف مطالعه: از آنجايى كه هدف از از انجام

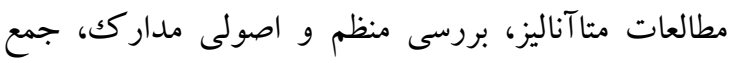
بندى كمى نتايج حاصل از هر مطالعه، تركيب نتايج مطالعات مختلف و فراهم كردن يكك تفسير كلى نتايج مى نى

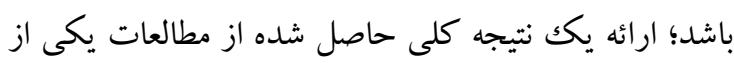
نكات قوت مطالعه حاضر مى باشد. افزايش آشنايى و آكاهى محققين و دانشخاهيان در خصوص تاثير تعيين كننده هاى اجتماعى سلامت بر بيامدهاى باردارى و بيشنهاد انجام

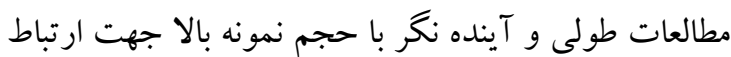

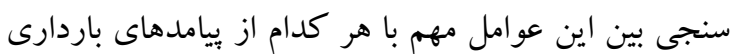
از ساير نقاط قوت مطالعه حاضر مى باشد. از محدويت هاى

\section{References}

1. Philip Blumenshine M, Egerter S, Barclay CJ, Cubbin C, Braveman PA. Socioeconomic Disparities in Adverse Birth Outcomes. Am J Prev Med 2010;39: 263-72.

2 . Devi S. New York moves to tackle shortage of primary-care doctors. Lancet 2008; 371: $801-2$

3 . Hutchinson EA, De Luca CR, Doyle LW, Roberts G, Anderson PJ, Group VICS. Schoolage outcomes of extremely preterm or extremely low birth weight children. PEDS 2013;131: 1053-61.

4. Katz J, Lee AC, Kozuki N, Lawn JE, Cousens S, Blencowe H, et al. Mortality risk in preterm and small-for-gestational-age infants in low-income and middle-income countries: a pooled country analysis. Lancet 2013; 382: 417-25. 
5. Lee AC, Katz J, Blencowe H, Cousens S, Kozuki N, Vogel JP, et al. National and regional estimates of term and preterm babies born small for gestational age in 138 low-income and middle-income countries in 2010. Lancet Glob Health 2013; 1: e26-e36.

6. Darling RD, Atav AS. Risk factors for low birth weight in New York state counties. Policy Politics Nurs Pract 2012; 13: 17-26.

7. Black RE, Allen LH, Bhutta ZA, Caulfield LE, De Onis M, Ezzati M, et al. Maternal and child undernutrition: global and regional exposures and health consequences. Lancet 2008; 371: 243-60

8. Christian P, Lee SE, Angel MD, Adair LS, Arifeen SE, Ashorn P, et al. Risk of childhood undernutrition related to small-for-gestational age and preterm birth in low-and middleincome countries. Int J Epidemiol 2013; 42: 1340-55.

9. Sharifi N, Dolatian M, Fathnezhad A, Pakzad R, Mahmoodi Z, Mohammadi nasrabadi F. Prevalence of Low Birth Weight in Iranian newborns: A systematic review and meta-analysis. IJWHR 2018; 6: 113-22.

10. Zarrati M, Shidfar F, Moradof M, Nejad FN, Keyvani H, Hemami MR, et al. Relationship between breast feeding and obesity in children with low birth weight. Iran Red Crescent Med J 2013; 15: 676-82.

11. da Fonseca CRB, Strufaldi MWL, De Carvalho LR, Puccini RF. Risk factors for low birth weight in Botucatu city, SP state, Brazil: a study conducted in the public health system from 2004 to 2008. BMC Res Notes. 2012; 5: 60.

12. Dolatian M, Mirabzadeh A, Forouzan A, Sajjadi H, Alavi- Majd H, Moaf F. Preterm delivery and psycho-social determinants of health based on World Health Organization model in Iran: a narrative review. Glob J Health Sci 2013; 5: 52-64.

13.Motlagh M, Olaii-manesh A, Beheshtian M. Health and social determinants of health strategies for justice and fair opportunities for all. Secretariat of the social determinants of health and promote equity in health, Health Department of the Ministry of Health and Medical Education. Successful Publishing. 2008.

14. Sharifi N, Dolatian M, Mahmoodi Z, Mohammadi nasrabadi F. Gestational diabetes and Relationship social determinants of health with it, According to World Health Organization Model: Systematic Review. IJOGI 2017; 19: 6-18. [In Persian]

15. Sharifi N, Dolatian M, Fathnezhad kazemi A, Pakzad R. The Relationship Between The Social Determinants of Health With Preterm Birth in Iran Based on The WHO Model: A Systematic Review and Meta-analysis. IJWHR 2018; 6: 113-22

16. Solar O, Irwin A. A conceptual framework for action on the social determinants of health. Social Determinants of Health Discussion Paper 2 (Policy and Practice). Geneva. WHO 2010. Available from: URL: http://nccdh.ca/resources/entry/a-conceptual-framework.

17. Vettore MV, Gama SGNd, Lamarca GdA, Schilithz AOC, Leal MdC. Housing conditions as a social determinant of low birthweight and preterm low birthweight. Revista de Saúde Pública 2010; 44: 1021-31.

18. Khashan AS, McNamee R, Abel KM, Pedersen MG, Webb RT, Kenny LC, et al. Reduced infant birthweight consequent upon maternal exposure to severe life events. Psychosom Med 2008; 70: 688-94.

19. Hosseini SM, Biglan MW, Larkby C, Brooks MM, Gorin MB, Day NL. Trait anxiety in pregnant women predicts offspring birth outcomes. Paediatr Perinat Epidemiol 2009; 23: 55766.

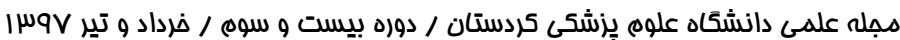


20. Rondo P, Ferreira R, Nogueira F, Ribeiro M, Lobert H, Artes R. Maternal psychological stress and distress as predictors of low birth weight, prematurity and intrauterine growth retardation. Eur J Clin Nutr 2003; 57: 266-72.

21. Silverman J, Decker M, Reed E, Raj A. Intimate partner violence victimization prior to and during pregnancy among women residing in 26 US states: associations with maternal and neonatal health. AJOG 2006; 195: 140-8.

22. Nkansah-Amankra S, Luchok KJ, Hussey JR ,Watkins K, Liu X. Effects of maternal stress on low birth weight and preterm birth outcomes across neighborhoods of South Carolina, 2000-2003. Matern Child Health J 2010; 14: 215-26.

23. Gordis L. Epidemiology. 4nd ed. Philadelphia: Saunders, 2008: 400.

24. DerSimonian R, Laird N. Meta-analysis in clinical trials. Control Clin Trials 1986; 7: 17788.

25. Begg CB, Mazumdar M. Operating characteristics of a rank correlation test for publication bias. Biometrics 1994:1088-101.

26. Egger M, Smith GD, Schneider M, Minder C. Bias in meta-analysis detected by a simple, graphical test. BMJ 1997; 315: 629-34.

27. Alizadeh M, Dastgiri S, Taghavi S, Khanlarzadeh E, Khamnian Z, Jafarabadi MA, et al. The Relationship between Social Determinants of Health and Pregnancy Outcomes: A Retrospective Cohort Study in Tabriz. JCRG 2014; 3: 152-7.

28. Eghbalian F. Low birth weight causes survey in neonates. Iran J Pediatr 2007; 17: 27-33

29. Mahmoodi Z, Karimlou M, Sajjadi H, Dejman M, Vameghi M, Dolatian M. Working Conditions, Socioeconomic Factors and Low Birth Weight: Path Analysis. Iran Red Crescent Med J 2013;15: 836-42.

30. Baheri B, Ziaie M, Zeighami -Mohammadi S. Effect of Domestic Violence on Pregnancy Outcomes among Pregnant Women Referring to Karaj Medical Centers. Hakim Res J 2012; 15: $140-6$.

31. Ranjbar H, Kohan M, Abas -Zadeh A, Arab M, Poryazdan-panah F. The study of violence against the mother and substance abuse during pregnancy and their association with pregnancy outcomes in mothers Kerman. Iran J Obstet Gynecol Infertil 2011; 14: 15-23.

32. Jafari F, Eftekhar H, Pourreza A, Mousavi J. Socio-economic and medical determinants of low birth weight in Iran: 20 years after establishment of a primary healthcare network. Public Health 2010; 124: 153-8.

33. Veghari G. Iron supplementation during pregnancy and birth weight in Iran: A retrospective study. Pak J Biol Sci 2009;12: 427-32.

34. Vahdaninia M, Tavafian SS, Montazeri A. Correlates of low birth weight in term pregnancies: a retrospective study from Iran. BMC Pregnancy Childbirth 2008; 8: 1.

35. Roudbari M, Yaghmaei M, Soheili M .Prevalence and risk factors of low birth weight infants in Zahedan, Islamic Republic of Iran. East. Mediterr Health J 2007; 13: 838-45.

36. Zahed-pasha Y, Esmaiili-doki M, Haji-ahmadi M, Asgardoon G, Ghadimi R, Baleghi M, et al. The effect of risk factors on low birth weight infants. JBUMS 2004;6:18-24. [In Persian] 37. Golestan M, Akhavan Karbasi S, Fallah R. Prevalence and risk factors for low birth weight in Yazd, Iran. Singapore Med J 2011; 52: 730-3. [In Persian]

38. Tayebi T, Zahrani ST, Mohammadpour R. Relationship between adequacy of prenatal care utilization index and pregnancy outcomes. Iran J Nurs Midwifery Res 2013; 18: 360-6.

39. Fallah M, Afrouz G, Haidari G. Factors affecting birth weight infants in Yazd.1386. Toloo e Behdasht 2008; 3: 57-63. [In Persian] 
40. Maddah M, Karandish M, Mohammadpour-Ahranjani B, Neyestani T, Vafa R, Rashidi A. Social factors and pregnancy weight gain in relation to infant birth weight: a study in public health centers in Rasht, Iran. Eur J Clin Nutr 2005; 59: 1208-12.

41. Karimian S, Molamohammadi M, Jandaghi G. Prevalence and factors associated with low-weight newborns in the maternity Qom Province in 2000. Feyz 2004; 27: 76-80. [In Persian]

42. Alipour Z, Lamyian M, Hajizadeh E. Anxity during pregnancy: a risk factor for neonatal physical outcome. J Urmia Nurs Midwifery Fac 2011; 9: 30-8. [In Persian]

43. Nasiri Amiri F, Salmalian H, Hajiahmadi M, Ahmadi AM. Association between Prenatal Anxiety and Spontaneous Preterm Birth. JBUMS 2009; 11: 42-8. [In Persian]

44. Mozayeni M, Dorosty -Motlagh AR, Eshraghian MR, Davaei M. Relationship between food sequrity and stress in pregnant mothers and low birth weight infant in child birth conducted in 2020 in tehran akbar abadi hospital. Inter J Current Life Sci 2014; 4: 2915-21.

45. Rafati S, Borna H, Akhavirad M-B, Fallah N. Maternal determinants of giving birth to low-birth-weight neonates. Arch Iran Med 2005; 8: 277-81.

46. Hassan M, Kashanian M, Roohi M, Yousefi H. The relationship between domestic violence during pregnancy and neonatal outcomes. IJOGI 2013; 16: 21-9. [In Persian]

47. Jafari F, Eftekhar H, Fotouhi A, Mohammad K, Hantoushzadeh S. Comparison of maternal and neonatal outcomes of group versus individual prenatal care: a new experience in Iran. Health Care Women Int 2010; 31: 571-84.

48. Khodakarami N, Naji H, Dashti M, Yazdjerdi M. Woman abuse and pregnancy outcome among women in Khoram Abad, Islamic Republic of Iran. East Mediterr Health J 2009; 15: 622-8.

49. Dolatian M, Gharache M, Ahmadi M, Shams J, Alavi Majd H. Relationship between partner abuse during pregnancy and pregnancy outcomes. HMJ 2010; 13: 261-9. [In Persian] 50. Ansari H, arisay Z, Rahimi E, Rakhshani F. The relationship between violence during pregnancy and low birth weight: a case control study. JJUMS 2008; 6: 17-27. [In Persian] 51. Zeyghami B, Tabatabaee H, Parisay Z. A Study on Correlation Of Mothers Risk Factors With Low Birth Weight of Newborns at a Multile Regression Model in Kohghiloyeh and Boyerahmad Province in 2004-2005. Armaghane-Danesh 2005; 11: 37-45. [In Persian]

52. Faramarzi M, Esmaelzadeh S, Mosavi S. Prevalence, maternal complications and birth outcome of physical, sexual and emotional domestic violence during pregnancy. Acta Med Iran 2005; 43: 115-22.

53. Ramezanzadeh F, Tavafian S, Vahdaninia M, Shariat M, Montazeri A. Maternal and fetal outcomes of narcotic substance abuse, cigarette smoking, and unsafe drugs. Hakim Res J 2007; 10: 9-16. [In Persian]

54. Taheri F, Kazemi T. Risk Factors for Low Birth Weight in Birjand, Iran (a case-control study). J Birjand Univ Med Sci 2007; 14: 9-15.[In Persian]

55. Mirza-Rahimi M, Saadati H, Barak M, Abasgholi-Zadeh N, Azami A, Enteshari A. The incidence and causes of low birth weight infants in the hospitals of Ardabil in 2006. J Ardabil Univ Med Sci 2008; 9: 69-79. [In Persian]

56. Roudbari M, Yaghmaei M, Soheili M. Prevalence and risk factors of low birth weight infants in Zahedan, Islamic Republic of Iran. East Mediterr Health J 2007; 13: 838-45.

57. Zahed-pash Y, Esmaili-Doki M-R, HajiAhmadi M, Asgardoon G, Ghadimi R, Baleghi M, et al. The effect of some risk factors for low birth weight (LBW). JBUMS 2004; 6: 24-18. [In Persian]

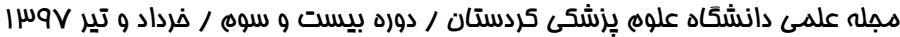


58. Falah M, Afrooz G, Heydari G. Factors affecting birth weight in Yazd province in 2007. J JSSU 2008; 16: 31-5.

59. Abdollahi F, Abhari FR, Delavar MA, Charati JY. Physical violence against pregnant women by an intimate partner, and adverse pregnancy outcomes in Mazandaran Province, Iran. J Family community Med 2015;22(1):13-8.

60. Mirzarahimi M, Hazrati S, Ahmadi P, Alijahan R. Prevalence and risk factors for low birth weight in Ardabil, Iran. IJN 2013;4:18-23.

61. Kramer MS, Goulet L, Lydon J, Séguin L, McNamara H, Dassa C, et al. Socioeconomic disparities in preterm birth: causal pathways and mechanisms. Paediatr. Perinat Epidemiol 2001;15:104-23.

62. Yadegari L, Dolatian M, Mahmoodi Z, Shahsavari S, Sharifi N. The Relationship Between Socioeconomic Factors and Food Security in Pregnant Women. Shiraz E-Med J 2017; 18: e41483.

63. Berghella V, Roman A, Daskalakis C ,Ness A, Baxter JK. Gestational age at cervical length measurement and incidence of preterm birth. Obstet Gynecol 2007; 110: 311-7.

64. Banaian S, Parvin N. The Investigation of the Relationship Between Mental Health Condition and Martital Satisfaction. Sci J Hamdan Univ Med Sci 2006; 14: 52-62. [In Persian]

65. Sharifi N, Dolatian M, Mahmoodi Z, Nasr Abadi FM, Mehrabi Y. The relationship between social support and food insecurity in pregnant women: a cross-sectional study. J Clin Diagn Res 2017; 11: IC01-IC06.

66. Divney AA, Sipsma H, Gordon D, Niccolai L, Magriples U, Kershaw T. Depression during pregnancy among young couples: the effect of personal and partner experiences of stressors and the buffering effects of social relationships. J Pediatr Adolesc Gynecol 2012; 25: 201-7.

67. Coussons-Read ME, Okun ML, Nettles CD. Psychosocial stress increases inflammatory markers and alters cytokine production across pregnancy. Brain Behav Immun 2007; 21: 343 50.

68. Dominguez TP, Schetter CD, Mancuso R, Rini CM, Hobel C. Stress in African American pregnancies: testing the roles of various stress concepts in prediction of birth outcomes. Ann Behav Med 2005; 29: 12-21.

69. Huth-Bocks AC, Levendosky AA, Bogat GA. The effects of domestic violence during pregnancy on maternal and infant health. Violence Vict 2002; 17: 169-85.

70. Akrami MNZ. Prevalence of physical violence against pregnant women and effects on maternal and birth outcomes. Acta Medica Iranica 2006; 44: 95-100.

71. Brown SJ, Yelland JS, Sutherland GA, Baghurst PA, Robinson JS. Stressful life events, social health issues and low birthweight in an Australian population-based birth cohort: challenges and opportunities in antenatal care. BMC Public Health 2011; 11: 196.

72. Bhutta ZA, Darmstadt GL, Hasan BS, Haws RA. Community-based interventions for improving perinatal and neonatal health outcomes in developing countries: a review of the evidence. Pediatrics 2005; 115: 519-617.

73. Toughyani R, Ramezani MA, Izadi M, Motie Z. The effect of prenatal care group education on pregnant mothers' knowledge, attitude and practice. J Med Educ 2008; 7: 31724. 